\title{
The Study Process of Equalizing Temporary Sprinkler and a Substantiation of Parameters of Working Bodies
}

\author{
Manabaev NT and Baimakhanov $\mathrm{K}^{*}$ \\ Shymkent South Kazakhstan State University, Kazakhstan
}

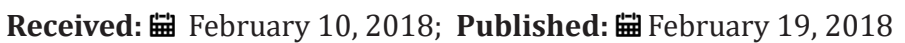

*Corresponding author: Baimakhanov K, Shymkent South Kazakhstan State University, Kazakhstan

\begin{abstract}
The article examines the processes of cutting temporary sprinklers for irrigation of crops, periodic equalizer them after watering, as well as provided the identified deficiencies and irrigation network equalizers, agro-technical requirements to be met by irrigation network and equalizers temporary sprinklers. A new technology sprinklers equalizing time to address their weaknesses, as well as workflow alignment. Currently operating equalizers cannot perform quality work on the proposed authors equalizing technology. Therefore, there is need for scientific substantiation of new working body's equalizers. Research was conducted manufacture different variants of experimental models of working body for alignment sprinklers and study parameters of working body equalizer performing the proposed technology alignment. In justifying the blade parameters used geometrical, physical and mathematical modeling techniques based on the principle of similarity. After conducting experiments obtained regression equation adequately describing the attractive resistance dump, placement depth of the top layer of dry soil dam in the recess, the value of the height irregularities after equalizing. The result proved the rational parameters of heap equalizer temporary sprinkler, which performs the proposed technology equalizing. These reasonable working body parameters recommended for use in development activities (R \& D) in the manufacture of equalizer model samplesopment of eroded and erosive dangerous soils of the foothill zones, carried out based on soil erosion surveys of the farms of the republic.
\end{abstract}

Keywords: Temporary irrigation network equalizer; Technology; Dam; Soil; Humidity; Blade; Study parameters; Rational parameters

\section{Introduction}

It is known that in the cotton growing area, particularly in the area of the old irrigation, furrow irrigation is now necessary to cut the time for each irrigation system watering, and watering after Equalizing required for the purpose could pass row units. In accordance with technological maps for cotton cultivation during the growing season is carried out up to 6 irrigations, respectively as much time and cut time equalize sprinklers [1,2].

Agro-technical requirements to be met by temporary Sprinklers are as follows:

a) Ensure maximum throughput capacity.

b) Efficiency (Filtration, evaporation, reset, etc.).

c) Of inscribed in the technical process of cultivation of cotton and other crops.

\section{d) Mechanization of cutting and equalizing etc.}

The bulk of the temporary irrigation network is cut before the first watering. At this time, the soil moisture in the layer of $0-50 \mathrm{~cm}$ is $70-75 \%$ of its field capacity. After processing of coming autumn plowing to a depth of $30 \mathrm{~cm}$ and pre-processing (harrowing or woeful with harrowing), so the soil crumbles easily when exposed to the working bodies and satisfactorily formed at the first cutting temporary sprinkler. This ensures the correct flow of water for the first watering as it requires minimum irrigation rate: $600-700 \mathrm{~m}^{3}$ / ha/2.7. After vegetation irrigation due to high soil moisture and sedimentation due to the passage of row with the Rotary machine processing after equalizing temporary sprinkler at the bottom of its recess is formed monolithic waterlogged soil environment. Therefore, during the subsequent cutting temporary sprinklers on 
the previous channel has not provided sufficient soil and crumbling levees new sprinkler is a conglomeration of large clumps and lumps that do not allow raising the level and enhancing the flow of water on sprinklers for irrigation norm $1000-1200 \mathrm{~m}^{3} /$ ha and effectively use the full cross-section of the temporary sprinkler.

After watering in the recess is a certain volume of water, at which drying takes time, which affects the dynamics of soil moisture in the excavation area after equalizing, and hence on the quality of the subsequent cutting dam boo harrowing temporary sprinkler. Depending on the water content in the soil greatly change friction coefficients of the soil and ground steels, hardness, and resistance to deformation of the soil. Physical and mechanical properties of the freshly laid dam very different physical characteristics of her. Physical and mechanical properties of the soil in the temporary section of the sprinkler and transverse profiles trackside during slicing and equalizing temporary sprinklers are not well understood [3]. Therefore, we have identified some physical and mechanical properties of soil dams and temporary recess of the sprinkler after watering pot. Investigation processes of equalizing temporary sprinklers. The research results of scientists when cutting irrigation sprinklers produce quality dams mainly depends on the method of cutting temporary sprinklers working bodies, as well as their working schemes and settings.

According to research conducted by the process of opening and leveling of irrigation furrows revealed that at the opening of the furrow irrigation on the old site of the dam quality is directly dependent on the alignment technology of irrigation furrows. Dam quality depends on the soil structure, which should be fine that can be solved by providing improved filtration of water consistency. For irrigation, during the equalizing sprinkler irrigation dam top layer of soil, it is necessary to throw down on the wet bottom of irrigation furrow, and then it is possible to hypothesize a base layer of wet dike to turn on the top of the dam. Equalizer grader disadvantages such as studying and researching their working bodies to provide better performance, higher performance equalizing said the process of their options have been identified are unfounded, because of that, we see that the process is not performed equalizing quality. Therefore it is necessary to justify the parameters of working body's equalizers temporary irrigation networks exploring them more deeply [4-6].

Based on the above it follows the need to conduct research and to put the following problem:

a) Issledovanie these processes equalizing temporary irrigation networks.

b) Conduct a study on the justification theoretically equalizing parameters.

c) Investigation of technological processes equalizing temporary irrigation networks in practice.

d) Justification of the main parameters of the working parts in practice equalizing temporary irrigation networks.

Based on the study research processes equalizing temporary irrigation networks applied currently defined, they do not fully meet the requirements of agro-technical. When equalizing temporary irrigation networks does not provide the quality the dam during the second holds time of sprinklers on earlier site. This is because during the movement of soil sprinkler temporary dam in the recess, the soil layers were mixed and wet laid as a bottom recess moist soil dam base and upper layers of soil over dried (1) that subsequently leads to the formation of a monolithic soil environment, from which the subsequent cutting of large lumps are formed with slits crossed that is the cause of the low water-conserving ability of dams and does not allow to raise the level and enhance the flow of water, efficient use of the potential of temporary sprinkler limits productivity irrigators (Figure 1).

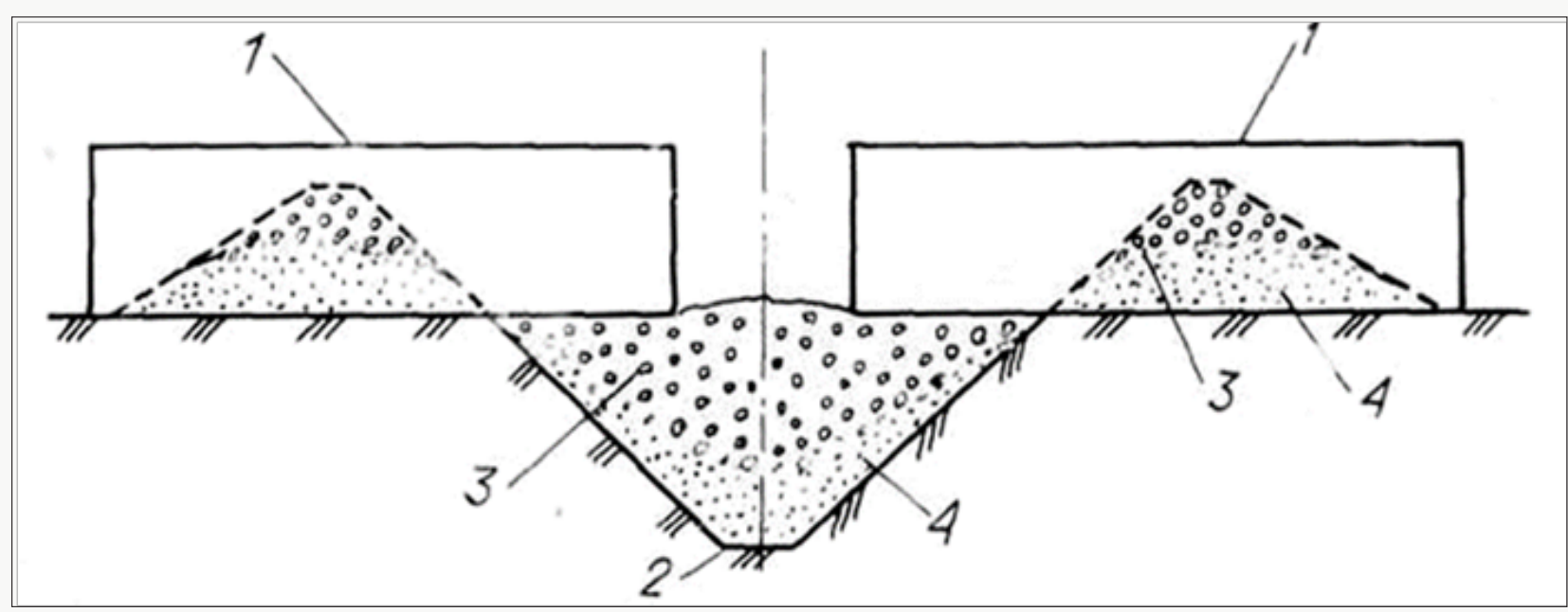

Figure 1: Existing technology equalizing temporary sprinkler: 1. Dumps, 2. Bottom recess, 3. Dry surface soil, 4 . Moist soil foundation. 
Disadvantages of the technique at the time equalizing sprinklers:

a) Non quality temporary dam sprinklers.

b) There is no possibility of raising the water level.

c) Does not allow full use of the capacity of the temporary irrigation canals.

d) Need for Additional manual labor.

e) An increase in water use costs.
As a way out of this situation in most households watering destroy boulders and reformats the temporary dam irrigation manual or mechanized cut them in two passes aggregates. With the passage of the second time over the dam is broken furrow profile. This method reduces the quality and increases the flow in two times. These drawbacks are eliminated while improving the water-holding capacity of dams, if equalizing temporary sprinkler to ensure the movement of the upper layers of the dam dry soil on the bottom of the main groove, and moist soil layers lay on top of its base. To do this, you must substantiate the operating parameters of the equalizer furrows.

\section{Methods of Laboratory Experiments}

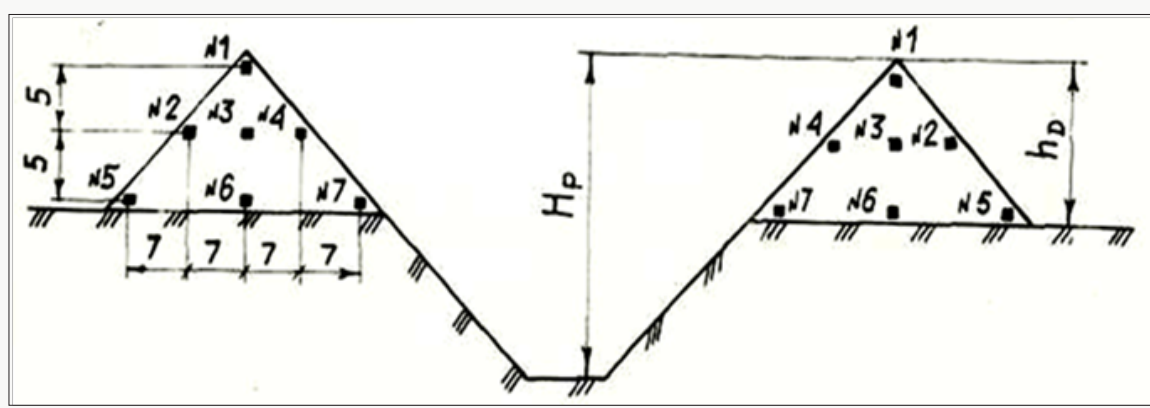

$\mathrm{H}_{\mathrm{p}}$-depth of the furrow, $\mathrm{h}_{\mathrm{D}}$-height dam, $\mathrm{N} \mathrm{O} \ldots 7$, numbered cubes

Figure 2: The circuit arrangement of cubes in a cross-section of the dam temporary sprinkler.

In the laboratory, studied the process of moving soil dam dumps equalizing, the dependence of the traction resistance of the angles of the blade to the direction of movement and to the horizon, the radius of curvature of the blade, the distance between the blades and speed guns. Move to the soil dams in the longitudinal $(\mathrm{Y})$, cross $(\mathrm{X})$ and vertical $(\mathrm{Z})$ directions studied by special cubes measuring $15 \times 15 \times 15 \mathrm{~mm}$, made of alabaster that were numbered, and were laid in temporary dam sprinklers as it is shown in (Figure 2). Cubes in each section had a different color and leveled in triplicate every $5 \mathrm{~m}$. When you create a background soil in the soil after loosening channel evenly moistened and flattened watering planner, mounted on a mobile frame of soil channel carts. Then cut a temporary irrigation. Before filming equalizer profile temporary sprinkler using the coordinate rails and fixed initial coordinates of cubes [4]. After passing equalizer rails installed in its original position and the new position of fixed blocks on the axes X, Y, Z. The difference between the final and initial positions cubes coordinate characterized the magnitude and direction of movement of the individual soil horizons dam. Figure 3 shows the temporary irrigation for experimentation g laid cubes. As shown by technological and theoretical research for high-performance technology equalizer temporary sprinkler dumps equalizer must provide offset and turnover over-dried topsoil dam on the wet bottom of the recess, and the moist soil dam foundation to lay on top of them.

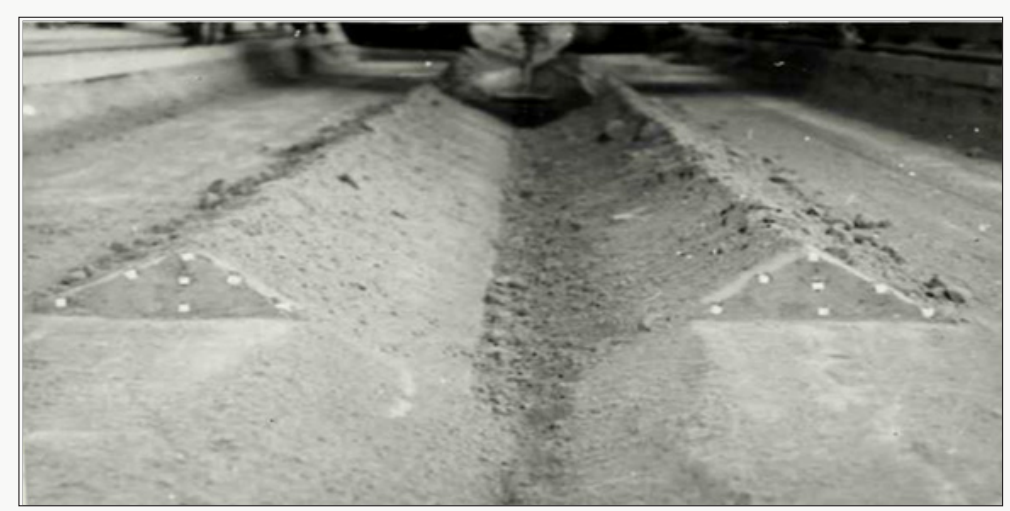

Figure 3: Temporary irrigation for laboratory experiments. 


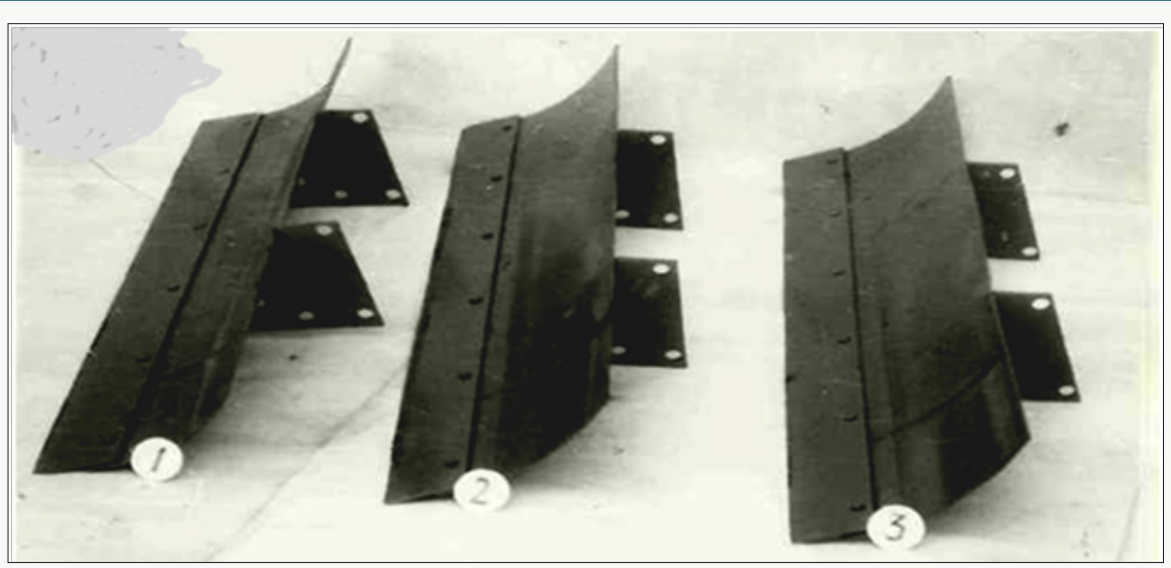

Figure 4: General view of experimental dumps 1-R1 = 150mm; $2-\mathrm{R} 2=225 \mathrm{~mm} ; 3-\mathrm{R} 3=300 \mathrm{~mm}$.

This prevents the formation of the recess in the lower layers of the monolithic waterlogged soil environment and re-cutting temporary sprinkler provided satisfactory crumbling of the soil, i.e. quality dam formation. Implementation of this technology possible only piles with rational, scientifically sound parameters. For clarification and determination of their rational values prove deny experimental studies of experimental models of different options equalizer dumps [7]. Experimental dumps produced by fitting them on the appropriate form size. General view of the fabricated piles is shown in Figure 4. The greatest influence on the movement and turnover of soil has a radius of curvature and angles forming the blade, the blade installation angle to the horizon and the direction of motion, between the blades and speed of movement. In the study of the work piles used geometrical, physical and mathematical modeling based on the principle of similarity. In view of the research equalizer temporary sprinkler depending on the working width averted, speed movement and conditions of its operation scale factor i to modeling determined by the approximate formula VI Balovneva.

$$
l_{\not D} \cdot K_{\ddot{\partial} \ddot{l}}^{-1} \cdot d^{-1} \geq i \leq\left(F_{H} \varepsilon F^{-1} K^{-1} \cdot 100\right)^{1 /\left(\ddot{I}+0,5 \ddot{I}_{\tilde{A}}\right)}
$$

Where $l_{H}=2,4 \mathrm{~m}$ - width equalizer
$\mathrm{Kd}=15,4$ - coefficient depending on the nature of the studied prism process of moving blade

$\mathrm{d}=2 \mathrm{~mm}$ - maximum linear dimension of soil fractions

$\mathrm{F}_{\mathrm{H}}=1,4 \cdot 104 \mathrm{H}-$ force equalizer

$\varepsilon=0,1$ relative experimental error

Ктп = 160 - maximum force on oscillogram

$\mathrm{Rmn}=5 \%$ - the accuracy class of the device

$\Pi=3$ - an indicator of the degree of which depends on the similarity of objects

Пг = 2 - an indicator of the degree of which depends on the statistical soil properties.

Construction height temporary sprinkler, equalized model blade, determined by the formula:

$$
\boldsymbol{H}_{M}=H_{H} \cdot i^{-1}=26
$$

Where $\mathrm{H}=52 \mathrm{~cm}$ - height of the construction of temporary sprinkler "Zara Niva natural equalizer blade.

According to (1) accept $\mathrm{i}=2$.

Figure 5: Blade with flanges for the study of changes in terms of the angle.

For laboratory studies were made models equalizer temporary sprinkler "allow you to set the blade in terms of an angle $\alpha=30^{\circ}$, $45^{\circ}$ and $60^{\circ}$ to the direction and angle $\delta=20^{\circ}, 45^{\circ} \times 70^{\circ}$ to the horizon (Figure 5). In all the experiments the depth size dumps equalizer soil was constant $\mathrm{hd}=12 \mathrm{~cm}$. The installation angle in the dumps varied from $30^{\circ}$ to $60^{\circ}$ to the direction of movement, and to the horizon-from $20^{\circ}$ to $70^{\circ}$, speed was varied from $1.11 \mathrm{~m} / \mathrm{s}$ to $2.23 \mathrm{~m} / \mathrm{s}$. Baseline speed blade models identified on the basis of earlier experiments equalizer in the unit with the tractor MT3-80 known formula VL Balovneva. 


$$
V_{M}=V_{H} \cdot i(1-0,5 p) 1,67-2-0.5==1.18 \mathrm{~m} / \mathrm{s}(3)
$$

Where $\mathrm{VH}_{\mathrm{H}}$ - speed movement of natural sample equalizer at equalizing temporary sprinkler. Selecting a blade angle to the horizontal direction and movement, radius of curvature, the distance between the blade and the speed gun in the study of the energy performance of the unit realized using experimental design. On the basis of prior information and the results of theoretical studies of selected multiple levels of varying (Table 1) Factors and levels of variation. In experiments using known B5 of polirepliks program containing 26 variants of experiments. Experiment planning matrix presented in Table 1 of Annex 2. After the implementation of the planning matrix had a re-processing results of the experiment, the calculation of the regression coefficients, assess their significance, check the reproducibility of the process and the adequacy of the hypothesis of the equation obtained by the well-known method in the PC computer Robotron-1715 Traction resistance blade equalizer determined with a help of specially developed strain gauge device (Figure 6). It consists of two mutually perpendicular first-horizontal 1 and 2 vertical tenzobalok with glued on them resistance strain gauges for determining the two projections (vertically and horizontal) forces acting on the blade equalizer. After the implementation of experiments, the following regression equations that adequately describe

Table 1: Factors and levels of variation.

\begin{tabular}{|c|c|c|c|c|c|c|}
\hline \multirow{2}{*}{ Factor } & \multicolumn{2}{|c|}{ Designation } & \multicolumn{3}{|c|}{ The level of factor } & \multirow{2}{*}{$\begin{array}{l}\text { Variation } \\
\text { Intervals }\end{array}$} \\
\hline & Natural & Conditional & -1 & 0 & +1 & \\
\hline 1. The installation angle heap plan, the degree of & a & $\mathrm{X} 1$ & 30 & 45 & 60 & 15 \\
\hline 2. The distance between the piles, and $X 2 \mathrm{~mm}$ & $\mathrm{a}$ & $\mathrm{X} 2$ & 0 & 400 & 800 & 400 \\
\hline 3. Heap installation angle to the horizon, degree & $\delta$ & X3 & 20 & 45 & 70 & 25 \\
\hline 4. The radius of curvature of the blade, $\mathrm{mm}$ & $\mathrm{R}$ & $\mathrm{X} 4$ & 300 & 450 & 600 & 150 \\
\hline 5. Soon, the movement, $\mathrm{m} / \mathrm{s}$ & $\mathrm{V}$ & X5 & 1,11 & 1,67 & 2,23 & 0,56 \\
\hline
\end{tabular}

\begin{tabular}{|c|}
\hline (II) \\
\hline
\end{tabular}

1-horizontal tenzobalki, 2-vertical tenzobalki

Figure 6: Driving strain gauges stickers' tenzobalku.

a) Traction resistance of blade

b ) $\vec{B}_{I}=8,51 \tilde{b}+2,684 \tilde{q}+0,994 \tilde{o}_{2}+1,172 \tilde{o}_{3}+1,107 \tilde{q} \tilde{\theta} 1,761_{1}^{2} \tilde{\theta} \tilde{b} 227{ }_{12}+1,621_{13}+$ (4)

c) The depth of placement of the upper layer of dry soil dam in the recess

$\mathrm{hc}=20,233+-0,629 \mathrm{~h} 2-0,629 \mathrm{~h} 30,611 \mathrm{~h} 4-0,646 \mathrm{~h} 1 \mathrm{~h} 2$ $-1,104 \times 1 \mathrm{~h} 4--0,771 \times 2 \times 3-0,688 \times 4 \times 5, \mathrm{~cm},(5)$

d) The value of irregularities after zaravnivaniya effusions

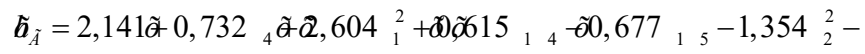
$-0,552 \tilde{o}_{2} \tilde{o}_{3}+0,906 \tilde{o}_{2} \tilde{o}_{5}+1,479 \tilde{o}_{4}^{2}+0,698 \tilde{o}_{4} \tilde{o}_{5}-1,354 \tilde{o}_{5}^{2}, \tilde{n} \grave{l}$

(6)
Analysis of the equations shows that the depth of placement of the upper layer of soil dam in the recess, the attractive resistance and the value of after equalizing is complex, depending on the different factors. In determining the values of the parameters of rational equalizing regression equation (6) by pulling resistance researched at least under the constraints of building parameters hc and collar nut) within

$$
\begin{aligned}
& 20 \leq \mathrm{h}_{\mathrm{c}} \leq 28 \mathrm{~cm} \\
& 0 \leq \mathrm{h}_{\mathrm{r}} \leq 10 \mathrm{~cm}
\end{aligned}
$$

and a fixed speed movement of the unit on the level of $\mathrm{Vp}=1.67 \mathrm{~m} / \mathrm{s}$. As a result, the following rational parameters heap equalizing temporary sprinkler (Table 2). On the basis of theoretical 
and experimental studies of these parameters can be considered rational and Share Desktop Authority equalizing temporary sprinklers. When making equalizing temporary sprinklers apply reasonable parameters for manufacturing.

Table 2: Results of the optimization parameters of the working body equalizer.

\begin{tabular}{|c|c|c|c|}
\hline \multirow{2}{*}{\multicolumn{2}{|c|}{ The Encode meaning }} & \multicolumn{2}{|c|}{ Natural } \\
\hline & & \multirow{2}{*}{$\begin{array}{c}\text { value } \\
36\end{array}$} & \multirow{2}{*}{$\begin{array}{c}\text { size } \\
\text { degree }\end{array}$} \\
\hline $\begin{array}{l}\text { 1.The installation angle heap plan, } \\
\text { the degree of }\end{array}$ & $-0,60$ & & \\
\hline $\begin{array}{l}\text { 2.The distance between the piles, } \\
\text { and } \mathrm{X} 2 \mathrm{~mm}\end{array}$ & $-0,20$ & 0,32 & $\mathrm{~m}$ \\
\hline $\begin{array}{l}\text { 3. Heap installation angle to the } \\
\text { horizon, degree }\end{array}$ & 0,80 & 65 & degree \\
\hline $\begin{array}{l}\text { 4. The radius of curvature of the } \\
\text { blade, } \mathrm{mm}\end{array}$ & 0,40 & 0,51 & $\mathrm{~m}$ \\
\hline 5. Soon, the movement, $\mathrm{m} / \mathrm{s}$ & 0 & 1,67 & $\mathrm{~m} / \mathrm{c}$ \\
\hline
\end{tabular}

\section{References}

1. Manabaev NT (1995) Improving technology equalizing temporary sprinklers and a substantiation of parameters tools. In NT Manabaev Abstract diss Candidate of tech. science p.17.

2. Manabaev NT (2014) Substantiation of the Parameters of Temporary Irrigation Ditch Leveltr Tools. Journal of Agricultural Science 6: 489-492.

3. Gyachev LV (1961) Theory moldboard plow surface. In LV Gyachev, Zernograd pp.318.

4. Bezborodov YG (2005) Energy, environmental and economic efficiency of water saving irrigation technology. Journal of Agricultural Sciences 6: 65-67.
5. Manabaev NT (2013) A study of soil displacement process depending on the installation position of the blade equalizer. In NT Manabaev Reports of the RAAS 2: 61-63.

6. Olgarenko GV (2011) The strategy for scientific and technological development of new techniques for irrigation activities in the implementation of the development program of land reclamation. Magazine Irrigation and Water Management 6: 5-8.

7. Akhmedzhanov MA, Manabaev NT (1992) Equalizing temporary sprinkler. Journal of Agriculture of Uzbekistan 8: 47-49.

\section{(c) (i) \\ This work is licensed under Creative Commons Attribution 4.0 License}

To Submit Your Article Click Here:

Submit Article
DOI: $10.32474 /$ CIACR.2018.01.000109

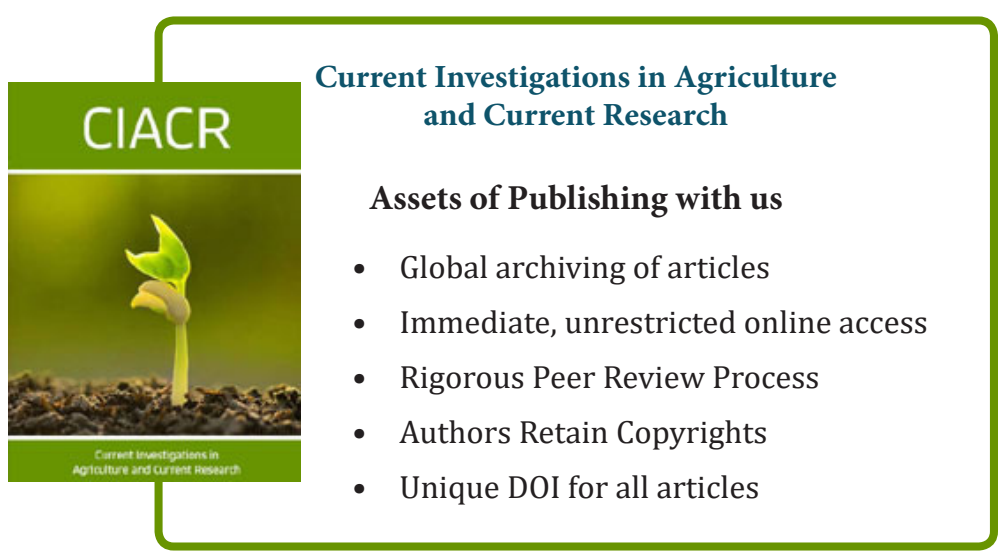

